\title{
THE EFFECT OF ST JOHN'S WORT (HYPERICUM PERFORATUM) ON CYTOCHROME P450 1A2 ACTIVITY IN PERFUSED RAT LIVER
}

\author{
Miroslav Dostalek $k^{\mathrm{a}, \mathrm{d}}$, Jana Pistovcakova ${ }^{\mathrm{b}}$, Jan Jurica ${ }^{\mathrm{b}}$, Alexandra Sulcova ${ }^{\mathrm{b}}$, Josef Tomandl* \\ a Department of Pharmacology, Faculty of Medicine, Masaryk University Brno, Czech Republic \\ ${ }^{b}$ Masaryk University, Central European Institute of Technology (CEITEC), c/o Masaryk University Brno \\ c Department of Biochemistry, Faculty of Medicine, Masaryk University Brno \\ ${ }^{d}$ Department of Biomedical and Pharmaceutical Sciences, University of Rhode Island, Kingston, RI, USA \\ E-mail:tomandl@med.muni.cz
}

Received: April 21, 2011; Accepted with revision: August 18, 2011

Key words: St John's wort/Hypericum perforatum/Cytochrome P450/Liver, isolated perfused/Rat

Aims. We previously reported the effect of St John's wort (Hypericum perforatum) standardised extract LI 160 on the activities of cytochrome P450 2C6, 2D2 and 3As (Dostalek et al., Life Sciences 2005;78(3):239-44). In this study, we aimed to assess the effect of St John's wort on the activity of cytochrome P450 1A2.

Methods. The isolated perfused rat liver model was used in our experiments with phenacetin as a marker substrate for cytochrome P450 1A2. Male Wistar rats were treated with St John's wort extract ( $100 \mathrm{mg} / \mathrm{kg}$, once daily for 10 days); comparative inhibitor (alpha-naphthoflavone, $100 \mathrm{mg} / \mathrm{kg}$ ) or comparative inducer (omeprazole, $30 \mathrm{mg} / \mathrm{kg}$ ).

Results. The rate of formation of acetaminophen was significantly inhibited by the use of St John's wort $(\mathrm{P}<0.001)$. In addition, St John's wort extract inhibited cytochrome P450 1A2 activity significantly more than the control inhibitor $(\mathrm{P}<0.001)$.

Conclusions. St John's wort significantly inhibited cytochrome P450 1A2 enzyme activity. It remains to be determined whether the co-administration of St John's wort extract and other medications or substrates for cytochrome P450 1A2 could result in significant drug interactions.

\section{INTRODUCTION}

The market and interest for herbal medicines and food supplements in the Western world has markedly increased in recent years, and, not surprisingly, reports of its interactions with conventional drugs have increased. The most well-known and documented example is the interaction of St John's wort with a variety of concomitantly used drugs ${ }^{1}$. Many case reports showing interactions between St John's wort and anticonvulsants, anti-HIV drugs, antidepressants, immunosuppressant agents and oral contraceptives have been published. Based on clinical and experimental data, the co-administration of St John's wort should be avoided particularly in patients who are taking drugs with a narrow therapeutic range ${ }^{2}$.

Although St John's wort (Hypericum perforatum) extracts are among the best characterized herbal medicines, numerous studies have reported the inductive and inhibitory effects of St John's wort on cytochrome P450 activity $^{1,3-5}$. Many clinical trials have shown that St John's wort induces P450 2C19, 2E1 and 3A4 with no effect on P450 2C9 (ref. $^{2}$ ). However, the literature is very contradictory concerning the effect of St John's wort on P450 1A2 enzyme activity. A single study associated treatment with St John's wort with a decreased plasma concentration of theophylline (a marker of P450 1A2) ( ref. $^{6}$ ), and this was later confirmed ${ }^{1,7}$. Further, an increased protein level of P450 1A2 after extended treatment with St John's wort has been reported by Shibayama et al. ${ }^{8}$ On the other hand, Wenk et al. ${ }^{9}$ and Arold et al. ${ }^{10}$ reported no change in P450 1A2 activity. In addition, in vitro data reported by Obach demonstrated the inhibitory effect of St John's wort constituents on P450 1A2 activity ${ }^{11}$.

There are many different brands of St John's wort available at the market, and as with any crude extract of a natural product, the content of its active ingredients varies considerably between manufacturers and between batches from the same manufacturer. The aim of our study was to describe the effect of commercially available Hypericum perforatum standardized extract LI 160 (containing $280 \mu \mathrm{g}$ of hypericin, $300 \mu \mathrm{g}$ of pseudohypericin, $6.5 \mathrm{mg}$ of hyperforin and $10 \mathrm{mg}$ of hyperosid in a single dose of $100 \mathrm{mg} / \mathrm{kg}$ ) on the activity of P450 1A2. In order to characterize this effect, isolated perfused rat liver was chosen as the study model.

\section{MATERIALS AND METHODS}

\section{Chemicals}

The standardized extract LI 160 was kindly provided by Lichtwer Pharma AG (Berlin, Germany); phenacetin, acetaminophen, alpha-naphthoflavone and omeprazole were purchased from Sigma Chemical Co. (St Louis, MO). All other chemicals and solvents used for HPLC assays were of HPLC or analytical grade and were obtained from Merck (Darmstadt, Germany) or Fluka Chemie AG (Buchs, Switzerland). All chemicals were used without 
further purification. All water solutions were prepared with Ultrapure water (Premier MFG Systems, Phoenix, AZ), filtered through a $0.45 \mu \mathrm{m}$ nylon membrane filter.

\section{Animals}

The experiment was carried out on male Wistar rats (weighing $220 \pm 25 \mathrm{~g}$, BioTest, Konarovice, Czech Republic) with free access to food and water under controlled environmental conditions (lights on from 6:00 am to $6: 00 \mathrm{pm}$, temperature $21-22{ }^{\circ} \mathrm{C}$, relative humidity $50-60 \%)$. After at least 10 days of adaptation to standard laboratory conditions, the rats were randomly allocated to 4 groups and treated intraperitoneally according to the following design: a) control group $(n=8)$ - sterile saline ( $2 \mathrm{ml} / \mathrm{kg}$ ), once daily for 10 days, the last dose was applied $24 \mathrm{~h}$ before liver preparation; b) St John's wort group (n $=10)-$ standardized extract LI $160(100 \mathrm{mg} / \mathrm{kg})$ once daily for 10 days, the last dose was applied $24 \mathrm{~h}$ before liver preparation; c) comparative inhibitor group $(\mathrm{n}=8)$ - sterile saline once daily for 10 days followed by a single dose of alpha-naphthoflavone used as a control inhibitor of P450 1A2 (100 mg/kg); d) comparative inducer group $(n=8)$ - sterile saline once daily for 5 days followed by five doses of omeprazole, a control inducer of P450 1A2 $(30 \mathrm{mg} / \mathrm{kg})$. The doses of control substrates were chosen because these were effective in a pilot study performed in our laboratory.

\section{Liver perfusion}

The isolated perfused rat liver model was used in our experiments. All experimental procedures were approved by the by the Czech Central Commission for
Animal Welfare according to Czech Act No. 246/1992 Coll. Aliquots of liver perfusate were collected at the $30^{\text {th }}$, $60^{\text {th }}$ and $120^{\text {th }}$ min of perfusion and stored at $-30{ }^{\circ} \mathrm{C}$ until analysis. All methods used in the study have been described elsewhere ${ }^{12}$. Liver viability was monitored in terms of constant perfusion pressure and rate, $\mathrm{pH}$ of perfusate, oxygen consumption, liver weight and a visual examination after finishing the perfusion.

\section{Chromatographic conditions}

Phenacetin $(12.5 \mathrm{mg} / \mathrm{l})$ was used as a specific marker of P450 1A2 activity. The HPLC determination of phenacetin and its respective metabolite was determined by a previously published and validated method ${ }^{13}$. Briefly, a mixture of $500 \mu \mathrm{l}$ of liver perfusate and $50 \mu \mathrm{l}$ of internal standard solution ( $40 \mu \mathrm{g} / \mathrm{ml}$ of chlorpropamide) and 4 $\mathrm{ml}$ of diethyl ether was vortexed (10 min at $2000 \mathrm{rpm}$ ) and then centrifuged $(5 \mathrm{~min}$ at $3000 \times g$ ). The organic phase was decanted and evaporated under a nitrogen stream, the residue was redisolved in $150 \mu$ of mobile phase (10 mM monobasic potassium phosphate, $\mathrm{pH} 4.5$ and acetonitrile, $65: 35, v / v)$. The analytes were separated in a Luna C18(2) analytical column $(150 \times 4.6 \mathrm{~mm}, 5 \mu \mathrm{m})$ from Phenomenex (Torrance, CA) at $40{ }^{\circ} \mathrm{C}$. Absorbance was monitored at $245 \mathrm{~nm}$. A flow rate gradient was used for the separation: $1.0 \mathrm{ml} / \mathrm{min}$ for $0-3 \mathrm{~min}$, followed by 1.8 $\mathrm{ml} / \mathrm{min}$ for $3-10 \mathrm{~min}$.

\section{Statistical analysis}

Phenacetin and acetaminophen perfusate concentrations vs. time data were analysed according to a noncompartment pharmacokinetic model. The data were

Table 1. Pharmacokinetic parameters of phenacetin and acetaminophen in the isolated perfused rat liver after administration of sterile saline ( $2 \mathrm{ml} / \mathrm{kg}$, i.p.), once per day for 10 days (control group); standardized extract LI 160 ( $100 \mathrm{mg} / \mathrm{kg}$, i.p.) once per day for 10 days (St John's wort group); sterile saline once per day for 10 days followed by a single dose of alpha-naphthoflavone (100 mg/kg, i.p.) (comparative inhibitor group); and sterile saline once per day for 5 days followed by five doses omeprazole (30 mg/kg, i.p.) (comparative inducer group).

\begin{tabular}{|c|c|c|c|c|c|c|}
\hline Group & $\begin{array}{l}\stackrel{\Xi}{0} \\
\stackrel{0}{\Xi} \\
\text { Z }\end{array}$ & 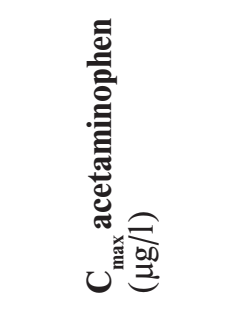 & 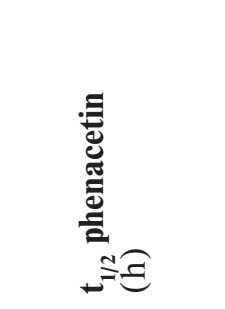 & 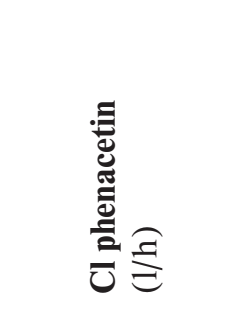 & 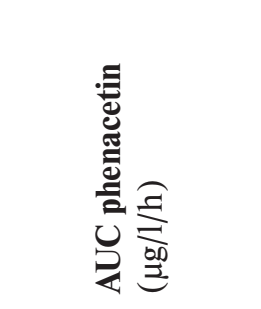 & 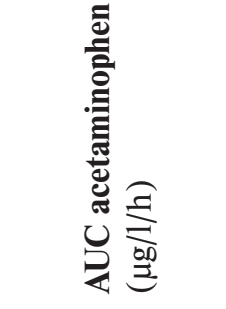 \\
\hline Control & 8 & $682 \pm 4.5$ & $2.4 \pm 0.13$ & $0.34 \pm 0.01$ & $12570 \pm 294$ & $639 \pm 21$ \\
\hline$\alpha$-Naphthoflavone & 8 & $490 \pm 48 * * *$ & $3.3 \pm 0.1 * * *$ & $0.19 \pm 0.008 * * *$ & $16321 \pm 241 * * *$ & $466 \pm 31 * * *$ \\
\hline Omeprazole & 8 & $3050 \pm 208 * * *$ & $0.7 \pm 0.09 * * *$ & $1.12 \pm 0.04 * * *$ & $9102 \pm 368 * * *$ & $1092 \pm 56 * * *$ \\
\hline Extract LI 160 & 10 & $237 \pm 29 * * *$ & $6.1 \pm 0.2 * * *$ & $0.06 \pm 0.002 * * *$ & $19654 \pm 249 * * *$ & $303 \pm 19 * * *$ \\
\hline
\end{tabular}

Data are expressed as means $\pm \mathrm{SEM}$ and statistical significance related to a control group. ${ }^{* * *}, \mathrm{P}<0.001$. $\mathrm{C}_{\max }$ acetaminophen - maximum acetaminophen perfusate concentration, $\mathrm{t}_{1 / 2}$ phenacetin - perfusate elimination half life of phenacetin, $\mathrm{Cl}$ phenacetin - clearance of phenacetin, AUC phenacetin - area under the entire perfusate concentration curve of phenacetin, AUC acetaminophen - area under the entire perfusate concentration curve of acetaminophen. 

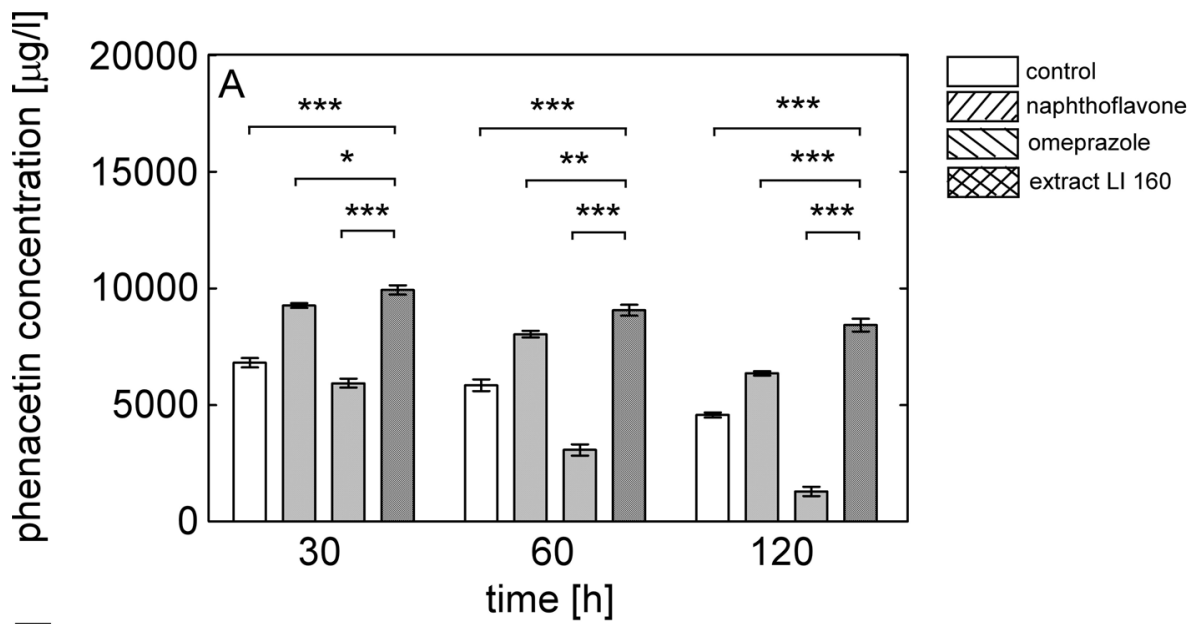

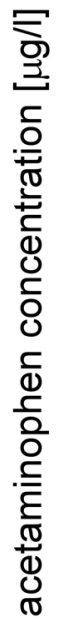
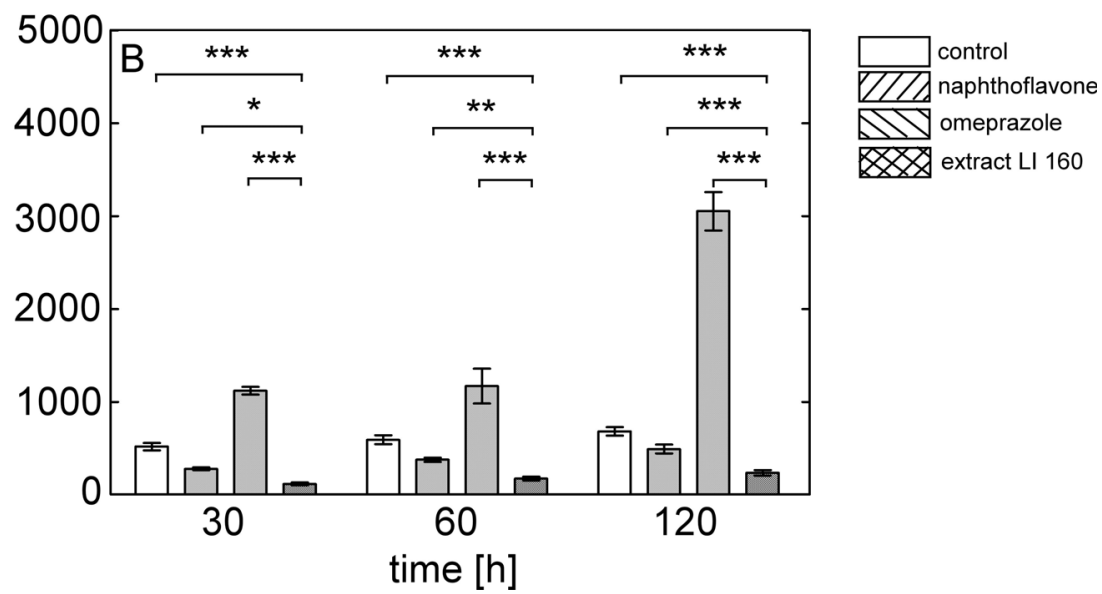

Fig. 1. Concentration of phenacetin (A) and acetaminophen (B) in perfusate medium from isolated perfused rat liver experiment after administration of sterile saline $(2 \mathrm{ml} / \mathrm{kg}$, i.p.), once per day for 10 days (control group); standardized extract LI 160 (100 mg/kg, i.p.) once per day for 10 days (St John's wort group); sterile saline once per day for 10 days followed by a single dose of alpha-naphthoflavone $(100 \mathrm{mg} / \mathrm{kg}$, i.p.) (comparative inhibitor group); and sterile saline once per day for 5 days followed by five doses of omeprazole $(30 \mathrm{mg} / \mathrm{kg}$, i.p.) (comparative inducer group). Data are expressed as means \pm SEM and statistical significance related to a control group. $* * * \mathrm{P}<0.001, * * \mathrm{P}<0.01,{ }^{*} \mathrm{P}<0.05$.

analysed by Kinetica version 4.1 (InnaPhase Corporation, Philadelphia, PA). The statistical analysis was carried out with SPSS software (version 16, Chicago, IL). Data are expressed as means \pm SEM. Values of $\mathrm{P}<0.05$ were considered to be significant.

\section{RESULTS AND DISCUSSION}

Standardized extract LI 160 was well-tolerated by all the animals, the body and liver weights of rats treated with St John's wort extract $(246.0 \pm 20.0 \mathrm{~g}$ and $10.5 \pm 1.5 \mathrm{~g}$, respectively) were similar to those in control rats $(250.0$ $\pm 15.0 \mathrm{~g}$ and $10.0 \pm 2.0 \mathrm{~g}$, respectively).

\section{Effect of St John's wort on P450 1A2 activity}

The effect of St John's wort extract LI 160 on the pharmacokinetics of phenacetin is demonstrated in (Fig. 1) and (Tab. 1). St John's wort extract LI 160 inhibited phenacetin deethylation via P450 1A2, which resulted in a significant increase in the AUC of phenacetin $(\mathrm{P}<0.001)$ and $\mathrm{t}_{1 / 2}$ of phenacetin $(\mathrm{P}<0.001)$. On the other hand, the use of extract LI 160 resulted in a significant decrease in the $\mathrm{Cl}$ of phenacetin $(\mathrm{P}<0.001)$ and AUC of acetaminophen $(\mathrm{P}<0.001)$. St John's wort extract LI 160 inhibited the P450 1A2 metabolic activity significantly more than the control inhibitor, alpha-naphthoflavone.

We previously reported that St John's wort resulted in a significant increase in P450 3As enzyme activity and to a significant inhibition of P450 2C6 activity ${ }^{12}$. In this experiment, St John's wort extract LI 160 was shown to powerfully inhibit P450 1A2.

Although St John's wort extracts are probably the best characterized herbal medicines, more than 150 ingredients, or groups of ingredients, have been identified so far $^{14}$. Still, $30-50 \%$ of its compounds are not yet structurally defined; some of these might well contribute to the drug-drug interactions ${ }^{14}$. Flavonoids are widespread 
compounds found in the plant kingdom. The total flavonoid content is dependent on such factors as growth environment, the quantities of various plant parts used, harvest time, drying procedures, and storage conditions ${ }^{15}$. St John's wort extract contains approximately 20 kinds of flavonoids some of which (hyperoside, isoquercitrin, quercitrin, quercetin) inhibit drug metabolizing enzymes (especially P450 1A and 2C) in human liver ${ }^{16}$. The flavonoid I3,II8-biapigenin has been shown to be a P450 1A2 inhibitor with $\mathrm{K}_{\mathrm{i}}=0.95 \pm 0.22 \mu \mathrm{M}$ (ref. ${ }^{11}$ ). A less potent inhibitory effect on P450 1A2 enzyme activity has been found for naphthodianthrone derivatives (hypericin, $\mathrm{K}_{\mathrm{i}}>100 \mu \mathrm{M}$ ), phloroglucinol derivatives (hyperforin, $\mathrm{K}$ $>100 \mu \mathrm{M}$ ) and phenolic acids (chlorogenic acid, $\mathrm{K}_{\mathrm{i}}>$ $100 \mu \mathrm{M})\left(\right.$ ref. $\left.^{11}\right)$.

A drug interaction occurring in vivo is likely if the maximum plasma unbound concentration $/ \mathrm{K}_{\mathrm{i}}>0.2\left(\right.$ ref. $^{17}$ ). The maximum plasma concentration $\left(\mathrm{C}_{\max }\right)$ of hyperforin is $0.17-0.50 \mu \mathrm{M}$ in humans following a single dose (300 mg) of standardized St John's wort extracts containing $5 \%$ hyperforin ${ }^{18,19}$. Thus, the less potent inhibitor could contribute more to the inhibition of P450 than the most potent inhibitor present in a minor amount. However, with a complex mixture of compounds, each compound in the preparation (depending on its relative abundance) could have an impact on drug-drug interactions.

The importance of uridine 5'-diphosphate-glucuronosyltranferases 1A1, 1A6, 1A9 and 2B15 in the biotransformation of acetaminophen has been demonstrated ${ }^{20-23}$. However, to the best of our knowledge, the effect of St John's wort extracts has not been studied. Thus, further studies are required to explain the effect of St John's wort extracts on the activity of phase II enzymes involved in the biotransformation of acetaminophen as their induction can influence the level of acetaminophen.

\section{CONCLUSIONS}

In conclusion, the standardized extract LI 160, a herbal preparation used in the treatment of depression, has been identified as a potent inhibitor of the metabolic activity of P450 1A2. However, it remains to be determined whether the co-administration of St John's wort and other medications could result in significant drug interactions via the inhibition of P450 1A2 activities.

\section{ACKNOWLEDGEMENTS}

This work was supported by Czech Ministry of Education Projects CEZ: J07/98:141100001, MSM: 0021622404, LC06023 and by Grant Agency of the Czech Republic: G3/447 and P206/10/0057. The authors wish to thank Lichtwer Pharma AG, Berlin, Germany for the sample of standardized extract LI 160. Quantitative analysis of standardised extract LI 160 was performed by Professor $V$. Suchy (Department of Natural Drugs, Faculty of Pharmacy, University of Veterinary and Pharmaceutical Sciences, Brno,
Czech Republic). The authors wish to thank Mrs J. Valova and Mrs J. Adamkova for excellent technical assistance.

\section{REFERENCES}

1. Gurley BJ, Gardner SF, Hubbard MA, Williams DK, Gentry WB, Cui Y, Ang CY. Cytochrome P450 phenotypic ratios for predicting herb-drug interactions in humans. Clin Pharmacol Ther 2002;72(3):276-87.

2. Borrelli F, Izzo AA. Herb-drug interactions with St John's wort (Hypericum perforatum): an update on clinical observations. AAPS J 2009;11(4):710-27.

3. Gurley BJ, Gardner SF, Hubbard MA, Williams DK, Gentry WB, Cui Y, Ang CY. Clinical assessment of effects of botanical supplementation on cytochrome P450 phenotypes in the elderly: St John's wort, garlic oil, Panax ginseng and Ginkgo biloba. Drugs Aging 2005;22(6):525-39.

4. Gurley BJ, Swain A, Hubbard MA, Williams DK, Barone G, Hartsfield F, Tong Y, Carrier DJ, Cheboyina S, Battu SK. Clinical assessment of P4502D6-mediated herb-drug interactions in humans: effects of milk thistle, black cohosh, goldenseal, kava kava, St. John's wort, and Echinacea. Mol Nutr Food Res 2008;52(7):755-63.

5. Mai I, Bauer S, Perloff ES, Johne A, Uehleke B, Frank B, Budde $\mathrm{K}$, Roots I. Hyperforin content determines the magnitude of the St John's wort-cyclosporine drug interaction. Clin Pharmacol Ther 2004;76(4):330-40

6. Nebel A, Schneider BJ, Baker RK, Kroll DJ. Potential metabolic interaction between St. John's wort and theophylline. Ann Pharmacother 1999;33(4):502.

7. Wang Z, Gorski JC, Hamman MA, Huang SM, Lesko LJ, Hall SD. The effects of St. John's wort (Hypericum perforatum) on human cytochrome P450 activity. Clin Pharmacol Ther 2001;70(4):317-26.

8. Shibayama Y, Ikeda R, Motoya T, Yamada K. St John's wort (Hypericum perforatum) induces overexpression of multidrug resistance protein 2 (MRP2) in rats: a 30-day ingestion study. Food Chem Toxicol 2004;42(6):995-1002.

9. Wenk M, Todesco L, Krahenbuhl S. Effect of St John's wort on the activities of P4501A2, P4503A4, P4502D6, N-acetyltransferase 2 , and xanthine oxidase in healthy males and females. Br J Clin Pharmacol 2004;57(4):495-9.

10. Arold G, Donath F, Maurer A, Diefenbach K, Bauer S, Henneickevon Zepelin HH, Friede M, Roots I. No relevant interaction with alprazolam, caffeine, tolbutamide, and digoxin by treatment with a low-hyperforin St John's wort extract. Planta Med 2005;71(4):3317.

11. Obach RS. Inhibition of human cytochrome P450 enzymes by constituents of St. John's Wort, an herbal preparation used in the treatment of depression. J Pharmacol Exp Ther 2000;294(1):88-95.

12. Dostalek M, Pistovcakova J, Jurica J, Tomandl J, Linhart I, Sulcova A, Hadasova E. Effect of St John's wort (Hypericum perforatum) on cytochrome P-450 activity in perfused rat liver. Life Sci 2005;78(3):239-44.

13. Jurica J, Konecny J, Zahradnikova LZ, Tomandl J. Simultaneous HPLC determination of tolbutamide, phenacetin and their metabolites as markers of cytochromes $1 \mathrm{~A} 2$ and 2C6/11 in rat liver perfusate. J Pharm Biomed Anal 2010;52(4):557-64.

14. Butterweck V, Schmidt M. St. John's wort: role of active compounds for its mechanism of action and efficacy. Wien Med Wochenschr 2007;157(13-14):356-61.

15. Brantner A, Grein E. Antibacterial activity of plant extracts used externally in traditional medicine. J Ethnopharmacol 1994;44(1):3540.

16. Lasker JM, Huang MT, Conney AH. In vitro and in vivo activation of oxidative drug metabolism by flavonoids. J Pharmacol Exp Ther 1984;229(1):162-70.

17. Ito K, Iwatsubo T, Kanamitsu S, Ueda K, Suzuki H, Sugiyama Y. Prediction of pharmacokinetic alterations caused by drug-drug interactions: metabolic interaction in the liver. Pharmacol Rev 1998;50(3):387-412. 
18. Barbenel DM, Yusufi B, O'Shea D, Bench CJ. Mania in a patient receiving testosterone replacement postorchidectomy taking St John's wort and sertraline. J Psychopharmacol 2000;14(1):84-6.

19. Breidenbach T, Kliem V, Burg M, Radermacher J, Hoffmann MW, Klempnauer J. Profound drop of cyclosporin A whole blood trough levels caused by St. John's wort (Hypericum perforatum). Transplantation 2000;69(10):2229-30.

20. Bock K W, Forster A, Gschaidmeier H, Bruck M, Munzel P, Schareck W, Fournel-Gigleux S, Burchell B. Paracetamol glucuronidation by recombinant rat and human phenol UDPglucuronosyltransferases. Biochem Pharmacol 1993;45(9):1809-14.

21. Munzel P A, Lehmkoster T, Bruck M, Ritter J K, Bock K W. Aryl hydrocarbon receptor-inducible or constitutive expression of human UDP glucuronosyltransferase UGT1A6. Arch Biochem Biophys 1998;350(1):72-8.

22. Fisher MB, Vandenbranden M, Findlay K, Burchell B, Thummel KE, Hall SD, Wrighton SA. Tissue distribution and interindividual variation in human UDP-glucuronosyltransferase activity: relationship between UGT1A1 promoter genotype and variability in a liver bank. Pharmacogenetics 2000;10(8):727-39.

23. Court MH, Duan SX, von Moltke LL, Greenblatt DJ, Patten CJ, Miners JO, Mackenzie PI. Interindividual variability in acetaminophen glucuronidation by human liver microsomes: identification of relevant acetaminophen UDP-glucuronosyltransferase isoforms. J Pharmacol Exp Ther 2001;299(3):998-1006. 
